\title{
Case Report: Human Recombinant Growth Hormone Therapy in a DSH Cat Presented With Dwarfism
}

\section{OPEN ACCESS}

Edited by:

Perumal Subramanian,

Annamalai University, India

Reviewed by:

Weinan Zhou,

University of Illinois at Urbana-Champaign, United States

Vijay K. Bharti,

Defence Institute of High Altitude Research (DIHAR), India

*Correspondence:

Martina Načeradská naceradska@af.czu.cz

Specialty section:

This article was submitted to Veterinary Pharmacology and

Toxicology,

a section of the journal

Frontiers in Veterinary Science

Received: 09 September 2021 Accepted: 20 October 2021 Published: 22 November 2021

Citation:

Načeradská M, Návojová Horáčková K and Fridrichová M

(2021) Case Report: Human

Recombinant Growth Hormone

Therapy in a DSH Cat Presented With

Dwarfism. Front. Vet. Sci. 8:773355

doi: 10.3389/fvets.2021.773355

\author{
Martina Načeradská ${ }^{1,2 \star}$, Kateřina Návojová Horáčková ${ }^{3}$ and Michaela Fridrichová ${ }^{4}$ \\ ${ }^{1}$ Department of Veterinary Sciences, Faculty of Agrobiology, Food and Natural Resources, Czech University of Life Sciences \\ in Prague, Prague, Czechia, ${ }^{2}$ Veterinární ordinace MVDr. Martiny Načeradské, Prague, Czechia, ${ }^{3}$ Veterinárni ordinace U \\ stř̆brné kočičky, Prague, Czechia, ${ }^{4}$ Department of Inorganic Chemistry, Faculty of Science, Charles University, Prague, \\ Czechia
}

A 6-month-old kitten, male, domestic shorthair cat was presented with dwarfism, ocular and nasal discharge, and Ascaris infestation. Congenital hyposomatotropism was diagnosed on the basis of serum level of insulin-like growth factor-1 (IGF-I). The cat was treated with human recombinant growth hormone for 9 weeks. After that, his liver enzymes became elevated, and the therapy was discontinued. His IGF-I levels were normal at the end of the therapy. Normal IGF-I was present 3 months after discontinuation of therapy with human recombinant growth hormone and even half a year after the discontinuation. All other comorbidities were addressed with the therapy. The cat is now the size of normal cats, living with the first author.

Keywords: dwarfism, human growth hormone, cat, hyposomatotropism, IGF-I

\section{INTRODUCTION}

There are several causes of dwarfism, "failure to thrive" in cats. Failure to grow can be caused by non-endocrine and endocrine disorders. Non-endocrine disorders are much more common and comprise malnutrition, dysfunction of nearly any organ in the body, and any chronic disease. Also included is constitutional dwarfism, which is a normal growth variation resulting in small stature in an otherwise healthy individual. Signs and symptoms seen at presentation can help direct further investigations. Presence of tachycardia or a heart murmur may be a sign of a cardiac abnormality. Regurgitation or vomiting may be the consequence of swallowing disorders such as megaesophagus or vascular ring anomaly. Diarrhea may suggest maldigestion or malabsorption caused by pancreatic disorders or intestinal parasites. Polydipsia and polyuria can be present in renal and hepatic disorders. When mental dullness is present, portosystemic shunt or central nervous system disorders should be suspected $(1,2)$.

Systemic diseases that can cause abnormal skeletal development in cats include nutritional imbalances such as nutritional secondary hyperparathyroidism of kittens on only meat diet, hypovitaminosis D (rickets in growing animals) (3), or hypervitaminosis A (4). There are several types of rickets in growing animals: hypophosphatemic due to loss via kidneys (5) and defects of metabolism of vitamin D-vitamin D-dependent rickets type 1 and type 2 (6), clinical signs are poor growth, soft bones, gait abnormalities, bowing of the legs, and enlarged growth plates, most commonly in the distal limbs (7). Hypervitaminosis A is seen in cats fed excessive amounts of liver and causes multiple bone exostoses, joint laxity, and impingement on nerves causing spinal cord or peripheral nerve and plexus disorders (4). Osteogenesis imperfecta is an inherited bone disease characterized by poor mineralization and excessive bone fragility. Clinically, the 
disease mimics nutritional secondary hyperparathyroidism (3). Inherited storage diseases, such as mucopolysaccharidoses, can cause long bone and/or vertebral column malformations. Cats with mucopolysaccharidosis present at less than a year of age with abnormal facial features, an abnormal gait, diffuse neurological disease, and dwarfism (3). Clues for the presence of mucopolysaccharidosis are seen in leukocytes as metachromic granules on peripheral blood smears (8).

Endocrine causes of dwarfism are much less common and are hypothyroidism, hyposomatotropism, diabetes mellitus, hypoadrenocorticism, and glucocorticoid excess (1). Hypothyroidism is caused by a developmental failure of the thyroid gland or by impaired thyroid hormone production. Clinical signs include disproportionate dwarfism (short body and limbs, big head), delayed tooth eruption, mental dullness, and lethargy $(9,10)$. Hypoadrenocorticism was described in one dwarf kitten with clinical signs of neurological disorders, with behavioral changes characterized by excessive fear, recurrent episodes of tremors, weakness, severe hypothermia, dull and scruffy fluffy hair coat, dysorexia, and pica (11).

Recently, the gene for feline dwarfism was described. Structure genome change interrupted UDP-glucose 6-dehydrogenase, a gene involved in the biosynthesis of glycosaminoglycans and was not described in human dwarfism yet (12).

Hyposomatotropism is extremely rare in cats, and only two cases have been described in the literature $(13,14)$. It is caused by lack of growth hormone $(\mathrm{GH})$ production in the pituitary gland. A recessively inherited disorder has been described in dogs and is seen as a mutation in the LHX3 gene in German shepherd dogs, Saarloos Wolfdogs and Czechoslovakian Wolfdogs (15, 16). Such changes have not yet been detected in cats. In hyposomatotropism, the impaired production of $\mathrm{GH}$ in the pituitary gland leads to a secondary deficiency in insulin-like growth factor-1 (IGF-I), which is produced in the liver. The consequence is proportional dwarfism in young cats and may be associated with a wide range of other clinical manifestations such as delayed closure of growth plates, delayed dental eruption, muscle atrophy, retention of secondary hair, lack of primary guard hairs, bilateral symmetrical alopecia, scaling, pyoderma, thin or hyperpigmented skin and testicular atrophy $(1,2,14)$, bilateral corneal opacity (13), and seizures due to hypoglycemia (14). Animals are usually presented at 3 to 5 months of age with retardation of growth or skin/coat abnormalities $(2,13,14,17)$.

The diagnostic approach to a dwarf kitten include hematology, serum biochemistry, and urinalysis. Results can aid in identifying renal or liver disease, diabetes mellitus, or others. These tests are usually unremarkable in feline pituitary dwarfism (1). In dogs, azotemia, proteinuria and low specific gravity was observed due to abnormal glomerular development and impaired renal function (2). In one cat, hypoglycemia was described at presentation (14). Fasting hypoglycemia was described in children too (18). Diagnostic evaluation of the skeleton might be needed to evaluate the presence of delayed epiphyseal closure in long bones. Abdominal ultrasound is indicated to exclude other differential diagnoses, such as liver or renal disease (2, 19). Advanced imaging techniques, such as magnetic resonance imaging (MRI) or computed tomography (CT) of the brain, may be useful in diagnosing pituitary dwarfism; in canine cases, the presence of pituitary cysts is usually observed $(2,20)$.

In terms of endocrine testing, a feline growth hormone (GH) assay has been validated, but is not freely available (21). Moreover, the determination of a single basal GH concentration has little diagnostic value due to its pulsatile secretion pattern. It has been demonstrated in dogs that there is overlap with healthy controls (22). In dogs, stimulation tests using GHRH and other substances are used $(2,20)$, but none of these tests have been used in cats (1). The determination of insulin-like growth factor (IGF-I) is more reliable because of its non-pulsatile secretion and longer half-life $(2,19)$. Therefore, the measurement of serum IGF-I concentrations is very useful in determining the level of activity of the somatotropic axis (23). In two diagnosed cats with hyposomatotropism, serum IGF-I was significantly lower [ $<25 \mathrm{ng} / \mathrm{ml}(14),<16 \mathrm{ng} / \mathrm{ml}$ (13)]. In one reported hypothyroid cat, IGF-I levels were lower too (104 ng/ml, RR 185-525 ng/ml) (24) and normalized with therapy for hypothyroidism. Therefore, evaluation of thyroid gland function is needed to exclude hypothyroidism. The IGF-I evaluation has several limitations since it can be influenced by age, sexual maturity, body size, nutritional status, and illness (1).

The most important effect of $\mathrm{GH}$ therapy is to promote growth (height velocity), but GH has also important metabolic effects. Although generalized growth is stimulated, it is not evenly distributed among the protein, lipid, and carbohydrate compartments. In $\mathrm{GH}$-deficient children, hGH therapy results in decreased body fat and increased fat free mass, including muscle and bone. Thus, proper GH secretion probably has major developmental influences on later health risks, including cardiovascular diseases and osteoporosis. The ability of insulin to promote fatty acid synthesis is antagonized by GH. Growth hormone induces a rapid loss of fat due to stimulation of lipolysis and reciprocal antagonism of the lipogenic actions of insulin (25).

In dogs, antibody formation precludes the use of recombinant human $\mathrm{GH}$ (26). Administration of porcine $\mathrm{GH}$ does not

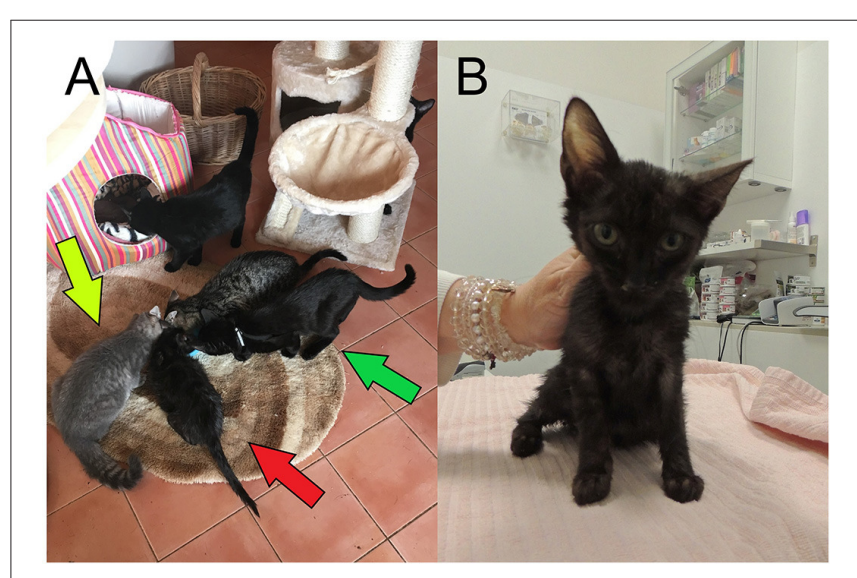

FIGURE 1 | (A) Patient at age 6 months (red arrow), two of his litter mates (green arrow), and another cat of the same age (yellow arrow). (B) Patient at age 6 months in detail. 
result in antibody formation because the amino acid sequence of porcine $\mathrm{GH}$ is identical to that of canine $\mathrm{GH}$ (27). The recommended dosage may result in $\mathrm{GH}$ excess and side effects, such as DM. Therefore, monitoring of plasma GH and glucose concentrations is recommended three times during each week of treatment (20).

Human growth hormone has been used in GH-deficient children, adolescents, and adult since 1958. Human recombinant $\mathrm{GH}$ (rhGH) was approved in 1985 (25). There are a few described side effects observed in therapy of GH deficiency, such as influence of glucose metabolism, since GH physiologically antagonizes insulin effect in glucose and lipid metabolism by stimulating glycogenolysis and lipolysis, and inhibiting glycogenesis and lipogenesis. Thus, treatment with rhGH is assumed to induce insulin resistance (28). Another adverse effect is prepubertal gynecomastia, which is rare and self-limited in treated children (29). Slipped capital femoral epiphysis (SCFE) is defined as a posterior and inferior displacement of the proximal femoral epiphysis on the femoral neck. It occurs more frequently in periods of rapid height gain (30). Children with GH deficiency are more prone to the development of SCFE especially when treated with rhGH. Benign intracranial hypertension $(\mathrm{BIH})$ is the result of the physiological antidiuretic effect of $\mathrm{GH}$ and is more evident in patients that cannot support decrease in glomerular filtration rate. Normal children exhibit a mild transitory elevation in plasma renin activity and aldosterone, and rarely develop BIH (31). Malignancies could be another adverse effect as both $\mathrm{GH}$ and IGF-I have mitogenic and antiapoptotic properties, and there has always been a concern that rhGH might induce tumorigenesis (32).

This case is unique because it first reported about human recombinant growth hormone therapy in a cat. Moreover, we described the side effects published in human literature.

\section{CASE HISTORY}

A 6-month-old, domestic shorthair tomcat was presented with failure to grow, ocular and nasal discharge, and Ascaris infestation. He was half the size of his litter mates (Figure 1). Clinical examination showed $3 / 9$ body condition score, normal corneal opacity, pink moist mucous membranes, poor muscle development, and a body weight of $790 \mathrm{~g}$. According to the literature, the weight of a domestic cat should be $\sim 2.2 \mathrm{~kg}$ at this age (33). His fur was dull, and only an undercoat was present, primary guard hairs were missing and the skin was very thin and fragile. Mild alopecia was noted on the ventral neck and on his shoulders. A mild purulent ocular and nasal discharge was present. Both ear canals were filled with thick dark wax, and Otodectes cynotis mites were present. All teeth were

TABLE 1 | Blood biochemistry results.

\begin{tabular}{|c|c|c|c|c|c|c|c|c|}
\hline Test & $\begin{array}{l}12 / 01 \\
2019\end{array}$ & $\begin{array}{l}01 / 31 \\
2020\end{array}$ & $\begin{array}{c}02 / 16 \\
2020\end{array}$ & $\begin{array}{l}03 / 01 \\
2020\end{array}$ & $\begin{array}{c}05 / 14 \\
2020\end{array}$ & $\begin{array}{c}09 / 26 \\
2020\end{array}$ & $\begin{array}{c}\text { Reference } \\
\text { range }\end{array}$ & Unit \\
\hline Canine TSH & $<0.03$ & & 0.03 & & & & $<0.5$ & $\mathrm{ng} / \mathrm{ml}$ \\
\hline |GF-I & $<15.0$ & & 412 & & 323 & 453 & 50-665 & $\mathrm{ng} / \mathrm{ml}$ \\
\hline GLU & 5.51 & 5.63 & 5.82 & 5.61 & & & $4.11-8.84$ & $\mathrm{mmol} / \mathrm{L}$ \\
\hline SDMA & 24 & 8 & 11 & & & & $0-14$ & $\mu \mathrm{g} / \mathrm{dl}$ \\
\hline CREA & 55 & 147 & 103 & 75 & & & $71-212$ & $\mu \mathrm{mol} / \mathrm{L}$ \\
\hline UREA & 8.8 & 10.6 & 9.1 & 7.4 & & & $5.7-12.9$ & $\mathrm{mmol} / \mathrm{L}$ \\
\hline BUN/CREA & 40 & 18 & 22 & 25 & & & & \\
\hline PHOS & & 2.74 & 2.59 & 2.76 & & & $1.00-2.42$ & $\mathrm{mmol} / \mathrm{L}$ \\
\hline CA & & 2.52 & 2.52 & 2.62 & & & $1.95-2.83$ & $\mathrm{mmol} / \mathrm{L}$ \\
\hline TP & 69 & 69 & 68 & 72 & & & 57-89 & $\mathrm{g} / \mathrm{L}$ \\
\hline ALB & 26 & 26 & 26 & 27 & & & $22-40$ & $\mathrm{~g} / \mathrm{L}$ \\
\hline GLOB & 43 & 43 & 42 & 44 & & & $28-51$ & $g / L$ \\
\hline ALB/GLOB & 0.6 & 0.6 & 0.6 & 0.6 & & & & \\
\hline ALT & 86 & 155 & 416 & 158 & & & $12-130$ & $\mathrm{U} / \mathrm{L}$ \\
\hline AST & 56 & 85 & 156 & 52 & & & $0-48$ & $\mathrm{U} / \mathrm{L}$ \\
\hline ALKP & 95 & 173 & 174 & 215 & & & $14-111$ & $\mathrm{U} / \mathrm{L}$ \\
\hline GGT & & 3 & 0 & 0 & & & $0-4$ & $\mathrm{U} / \mathrm{L}$ \\
\hline TBIL & & $<2$ & 3 & 3 & & & $0-15$ & $\mu \mathrm{mol} / \mathrm{L}$ \\
\hline CHOL & & 2.40 & 2.55 & 3.07 & & & $1.68-5.81$ & $\mathrm{mmol} / \mathrm{L}$ \\
\hline $\mathrm{Na}$ & & & 157 & 157 & & & $150-165$ & $\mathrm{mmol} / \mathrm{L}$ \\
\hline K & & & 3.9 & 3.9 & & & $3.5-5.8$ & $\mathrm{mmol} / \mathrm{L}$ \\
\hline $\mathrm{Na} / \mathrm{K}$ & & & 41 & 40 & & & & \\
\hline $\mathrm{Cl}$ & & & 122 & 115 & & & $112-129$ & $\mathrm{mmol} / \mathrm{L}$ \\
\hline OsmCalc & & & 314 & 312 & & & & $\mathrm{mmol} / \mathrm{kg}$ \\
\hline T14 & 17 & & 25 & & & & 10-60 & $\mathrm{nmol} / \mathrm{L}$ \\
\hline
\end{tabular}


TABLE 2 | Blood hematology results.

\begin{tabular}{|c|c|c|c|c|}
\hline Date & $\begin{array}{l}12 / 01 \\
2019\end{array}$ & $\begin{array}{l}01 / 31 \\
2020\end{array}$ & $\begin{array}{c}\text { Reference } \\
\text { range }\end{array}$ & Unit \\
\hline RBC & 5.98 & 7.98 & $6.54-12.20$ & $\times 10^{12} / L$ \\
\hline HCT & 30.5 & 37.7 & $30.3-52.3$ & $\%$ \\
\hline HGB & 9.6 & 12.3 & $9.8-16.2$ & $\mathrm{~g} / \mathrm{dl}$ \\
\hline MCV & 51.0 & 47.2 & $35.9-53.1$ & $\mathrm{fl}$ \\
\hline $\mathrm{MCH}$ & 16.1 & 15.4 & $11.7-17.3$ & $\mathrm{pg}$ \\
\hline $\mathrm{MCHC}$ & 31.5 & 32.6 & $28.1-35.8$ & $\mathrm{~g} / \mathrm{dl}$ \\
\hline RDW & 22.8 & 24.2 & $15.0-27.0$ & $\%$ \\
\hline \%RETIC & 0.3 & 0.1 & & $\%$ \\
\hline RETIC & 17.9 & 10.4 & $3.0-50.0$ & $\mathrm{~K} / \mu \mathrm{I}$ \\
\hline RETIC-HGB & 16.5 & 19.2 & $13.2-20.8$ & pg \\
\hline WBC & 49.30 & 18.88 & $2.87-17.02$ & $\times 10^{9} / \mathrm{L}$ \\
\hline$\% N E U$ & 86.2 & 69.7 & & $\%$ \\
\hline \%LYM & 7.5 & 23.0 & & $\%$ \\
\hline$\%$ MONO & 5.9 & 4.9 & & $\%$ \\
\hline \%EOS & 0.2 & 2.0 & & $\%$ \\
\hline \%BASO & 0.2 & 0.4 & & $\%$ \\
\hline NEU & 42.53 & 13.17 & $2.30-10.29$ & $\times 10^{9} / \mathrm{L}$ \\
\hline LYM & 3.69 & 4.35 & $0.92-6.68$ & $\times 10^{9} / \mathrm{L}$ \\
\hline MONO & 2.29 & 0.92 & $0.05-0.67$ & $\times 10^{9} / \mathrm{L}$ \\
\hline EOS & 0.10 & 0.37 & $0.17-1.57$ & $\times 10^{9} / \mathrm{L}$ \\
\hline BASO & 0.08 & 0.07 & $0.01-0.26$ & $\times 10^{9} / L$ \\
\hline PLT & 424 & 311 & $151-600$ & $\mathrm{~K} / \mu \mathrm{l}$ \\
\hline MPV & 16.9 & 17.6 & $11.4-21.6$ & $\mathrm{fl}$ \\
\hline РCT & 0.72 & 0.55 & $0.17-0.86$ & $\%$ \\
\hline
\end{tabular}

deciduous. His dwarfism was proportionate, and his legs were proportionate to the rest of the body. Clinical examination was otherwise unremarkable.

Serum biochemistry showed high SDMA ( $24 \mu \mathrm{g} / \mathrm{dl}$, RR up to 14, Table 1), slightly elevated AST (56U/L, RR up to 48, Table 1), and T4 was low normal (tT4 $17 \mathrm{nmol} / \mathrm{L}, \mathrm{RR} 10-60$, Table 1). Calcium level was normal, and phosphorus level was slightly elevated (Table 1), but it is normal in growing animals (34). Furthermore, canine TSH was measured and was unmeasurably low (up to $0.03 \mathrm{ng} / \mathrm{ml}$ ). Insulin-like growth factor was also unmeasurably low (up to $15 \mathrm{ng} / \mathrm{ml}$ ). Hematology showed mild non-regenerative anemia (RBC $5.98 \times 10^{12} / \mathrm{L}, \mathrm{RR} 6.54-12$; HGB $9.6 \mathrm{~g} / \mathrm{dl}$, RR 9.8-16.2, HCT 30.5\%, RR 30.3-52.3, Table 2) and severe leukocytosis (WBC $49.3 \times 10^{9} / \mathrm{L}, \mathrm{RR} 2.87-17.02$, Table 2) with neutrophilia, left shift, and monocytosis. Blood smear confirmed leukocytosis with the presence of band neutrophil, mild toxic changes in the cytoplasm of neutrophils, mildly reactive lymphocytes, and platelet clots. Urine examination was unremarkable, UP:UC ratio was 0.06, urine culture negative, and USG 1.053. Urine sediment exam revealed five casts, a few epithelia, no crystals, erythrocytes, leukocytes, or bacteria. A fecal analysis, including flotation and ELISA examination for the presence of Giardia and Cryptosporidium spp., was negative.
Eye, throat, and nose swabs were performed for PCR for Mycoplasma, Ureaplasma, Chlamydia, FHV-1, and calicivirus. The results came back very highly positive for Mycoplasma spp. $\left(10^{7} / \mathrm{ml}\right)$, highly positive for FHV $-1\left(10^{4} / \mathrm{ml}\right)$, and mildly positive for Ureaplasma $\left(10^{3} / \mathrm{ml}\right)$. X-rays (Figure 2) showed the front legs to be similar to a 16-week-old cat and the hind legs similar to a 12-week-old cat according to the literature (35). Growth plate closure was slightly delayed, but the growth plates were not deformed. Ultrasonography of the abdomen did not reveal any pathology; liver and kidneys were of normal echogenicity and size.

Differential diagnoses included pituitary dwarfism, severe infection, ascarid infestation, and portosystemic shunt (less likely).

\section{DIAGNOSTIC ASSESSMENT}

Therapy with peroral antibiotics [amoxicillin-clavulanate $25 \mathrm{mg} / \mathrm{kg}$ BID (Noroclav, Norbrook, UK)], spiramycin $(75,000 \mathrm{IU} / \mathrm{kg})$, and metronidazole $(12.5 \mathrm{mg} / \mathrm{kg})$ orally once a day (fixed dose combination; Stomorgyl, Merial, France) was started and given for 10 days. The Ascaris and Otodectes infestation was treated with a spot-on preparation (selamectin, Stronghold, Zoetis, USA). Antibiotic treatment was changed once PCR results were received 10 days later. Pradofloxacine $3 \mathrm{mg} / \mathrm{kg}$ SID (Veraflox, Bayer, Germany) was given perorally for 3 weeks, but the therapy was not sufficient, as both Ureaplasma and Mycoplasma were still present at this point, and therapy was changed to doxycycline $10 \mathrm{mg} / \mathrm{kg}$ SID (compounded syrup from pharmacy) for 4 weeks. One month later, the cat was clinically cured, and PCR came back negative. Treatment for FHV-1 included two 1-week courses of famciclovir $62.5 \mathrm{mg}$ pro toto BID (Famvir, Novartis, Switzerland) and was later PCR negative.

After receiving the results of IGF-I assay, therapy with human recombinant growth hormone subcutaneously (Humatrope 36 IU (12 mg) $1 \times 3.15-\mathrm{ml}$ injection, Eli Lilly and Company, USA) was started. The cat received $1.6 \mathrm{mg}$ of human recombinant growth hormone pro toto twice weekly for 9 weeks. The dose was extrapolated from the human growth hormone-deficient pediatric patient dose of $0.24-0.37 \mathrm{mg} / \mathrm{kg} /$ week (36). Since the metabolism of hormones is much faster in cats than in humans $(37,38)$, the dose was 10 times higher than the maximum dose recommended in humans. During therapy, liver enzymes got elevated, and treatment was discontinued. After 7 weeks, the liver enzymes were mildly elevated (ALT 155 U/L, RR 12-130, AST 85 U/L, RR 0-48 and ALP 173 U/L, RR 14-111, GGT was normal, Table 1), and after 9 weeks, the enzymes were much higher (ALT 416 U/L, AST 156 U/L, ALP 174 U/L, GGT was normal, Table 1). Therapy with growth hormone was discontinued at 8 months of age (Figure 3). Within 2 weeks of growth hormone treatment cessation, liver enzymes decreased almost back to normal (ALT $158 \mathrm{U} / \mathrm{L}$, AST $52 \mathrm{U} / \mathrm{L}$, Table 1). IGF-I was measured at discontinuation of therapy, and it was within the normal reference range (412 ng/ml, RR 50-665, Table 1). Normal IGF-1 was present 3 months after discontinuation of therapy 

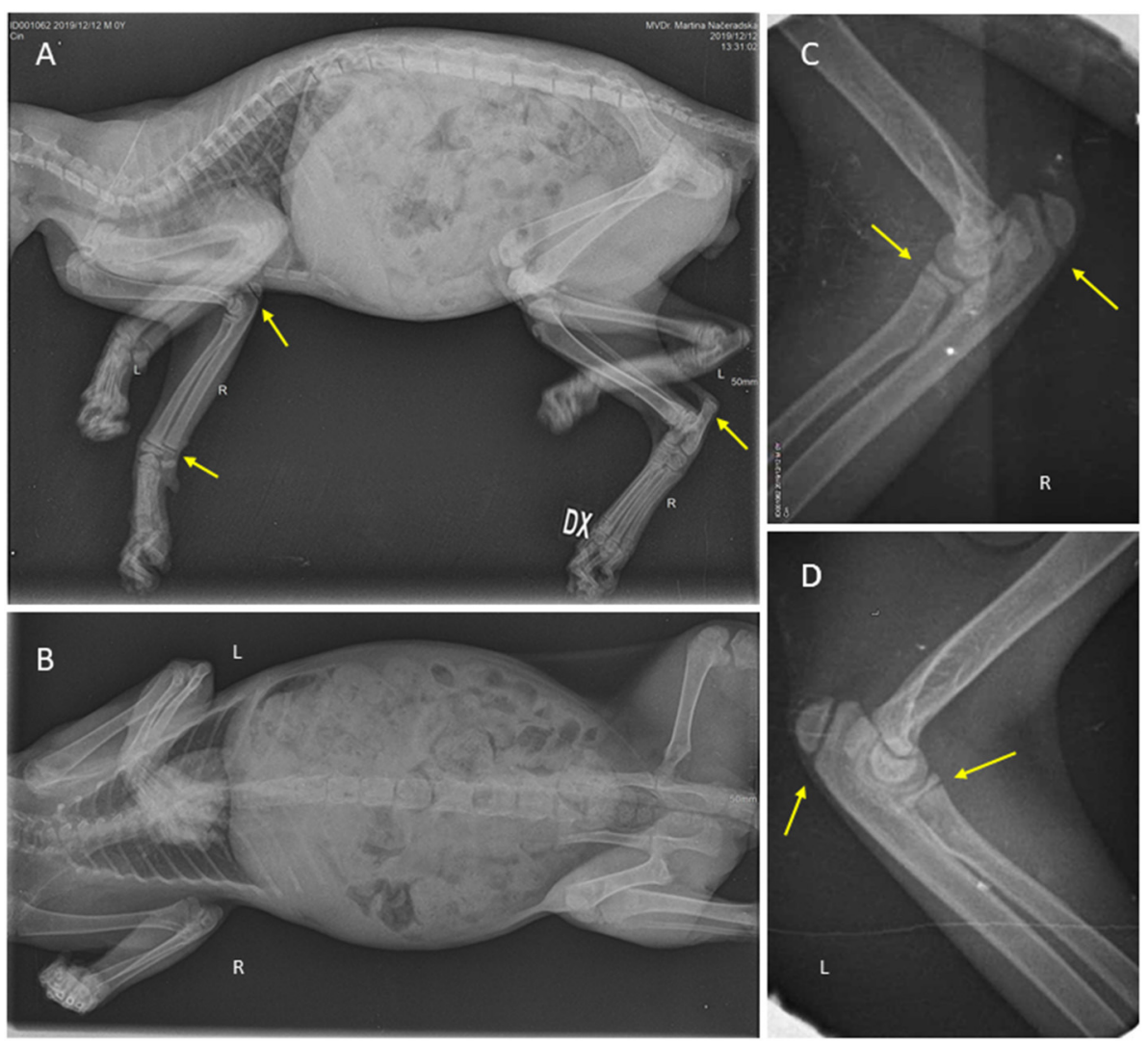

FIGURE 2 | Patient at the beginning of the therapy; whole-body X-ray show normal mineralization of the bones, and no fractures present. (A) Lateral position with marked normal growth plates (yellow arrows). (B) Ventrodorsal position. Elbows in detail. (C) Lateral position of the right elbow. (D) Lateral position of the left elbow, both with normal growth plates (yellow arrows).

(323 ng/ml) with human recombinant growth hormone as well as 6 months later $(453 \mathrm{ng} / \mathrm{ml})$.

Within the first 2 weeks of therapy, his permanent teeth started breaking through. Within a month, his fur changed, and primary guard hairs appeared, and the kitten became almost the same size of his littermates and got adopted by first author.

\section{DISCUSSION}

Malnutrition as a cause of dwarfism was less likely, since the kitten was first at the bowl, seen eating many times a day, and he was ravenous while eating and still is. That is maybe the reason why he never developed hypoglycemia described in one case of the cat with hyposomatotropism (14). Malnutrition in a small cat with a very good appetite being fed an adequate diet may be secondary to maldigestion or malabsorption (19), and since he had soft stool and Ascaris manifestation, this could have contributed to his small stature. He had severe leukocytosis with a left shift, which points to severe infection contributing to his dwarfism as described in the literature (1).
Mucopolysaccharidosis was ruled out, as metachromic granules should be seen in leukocytes on peripheral blood smear according to the literature (8). Moreover, he had no ocular manifestations as described in the literature (13).

Portosystemic shunt was one of the possible causes, but preand post-prandial bile acid screening was not performed as the kitten was recovering well on current therapy. Hepatic and renal disease were excluded via ultrasound, blood, and urine exam on first visit. He did not have any heart murmur, so heart disease was unlikely.

Skeletal X-rays revealed no signs of systemic diseases that can cause abnormal skeletal development except delayed proportional growth. No exostoses or deformations of the cartilage nor growth plates were seen. No demineralization or widening of growth plates was seen, so that discrepancy in minerals and vitamin D metabolism was not suspected. His calcium and phosphorus levels were also normal according to his age (34).

This kitten was severely underweight, which makes maldigestion or severe disease more likely, compared with endocrinopathies, where affected animals tend to be more overweight (8). Infection and inflammation were most likely 


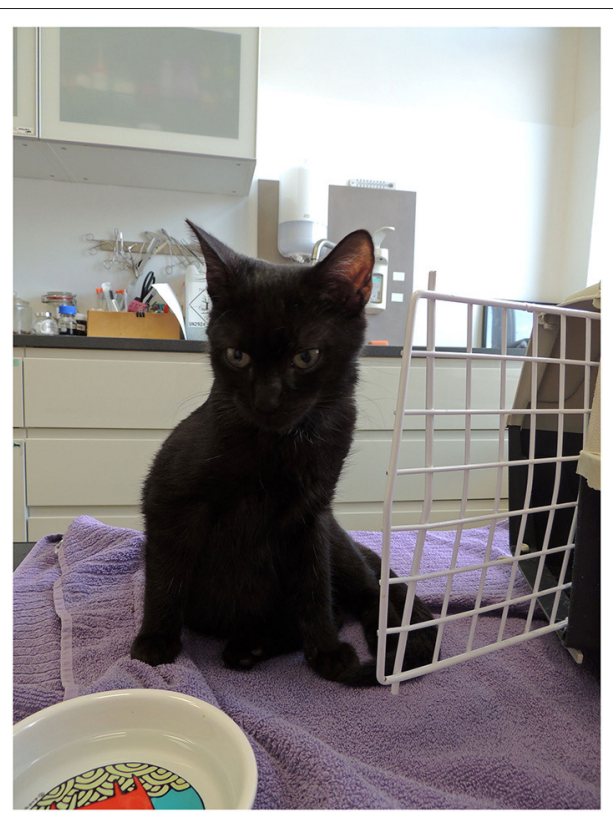

FIGURE 3 | Patient at age of 8 months, weight $2.7 \mathrm{~kg}$

contributing to the dwarfism. In conjunction with maldigestion, the cat suffered from severe infection, which contributed to the low IGF-I, and this explains why his IGF levels were normal even after withdrawal of growth hormone supplementation.

Congenital hypothyroidism was very unlikely since the dwarfism was not disproportionate, and the kitten was not mentally dull (10). The level of the thyroid hormone was in the low reference range at the beginning and normal while on therapy. His TSH was unmeasurably low at the beginning and later normal. There may be a connection between growth hormone treatment and thyroid function as described in one kitten treated for hypothyroidism (24). Congenital hypoadrenocorticism was unlikely since his minerals were normal (Table 1) compared with one described case (11), and he reacted well to the given therapy.

Since MRI or CT was not performed, hyposomatotropism could not be excluded as a cause of dwarfism in this cat. On xray, delayed closure of growth plates was seen, and he had delayed dental eruption, muscle atrophy, retention of secondary hair, lack of primary guard hairs, symmetrical alopecia on his neck, and thin skin, which is compatible with hyposomatotropism $(1,2,14)$. A recently described genome change as a cause of dwarfism could not be excluded, since the genome was not tested (12).

Hormone metabolism in the cat differs from that in humans. Absorption is similar, but the pharmacokinetics are different (37). Hormones are metabolized mainly via sulfatation, and this way of metabolism is much faster in cats than in dogs and humans (38). This is why the dose used was 10 times higher than in human medicine. Monitoring of IGF-I is recommended (1), and that is what we did. Interestingly, the normal IGF-I level remained stable even after discontinuation of the therapy with human recombinant hormone.
In human medicine, therapy is usually discontinued after the end of bone growth (39). In this case, therapy was discontinued earlier because of an elevation of liver enzymes. Some human adults still need GH therapy even in adulthood (39). In this feline case, this was not necessary. Self-limiting liver enzyme elevation was described in one study in human medicine in $3.8 \%$ of children on growth hormone therapy, and further investigation did not reveal any other cause. Liver enzymes normalized spontaneously within 3 to 6 months, without stopping the therapy (40). It seems like the same happened here: self-limiting liver enzyme elevation, which normalized with discontinuation of therapy.

In humans, the main side effect of therapy with human recombinant growth hormone is high glucose or diabetes mellitus because of its influence on glucose metabolism, none of which was observed in our case. Blood glucose was normal at the beginning of the therapy, 7 weeks later, and at the time of discontinuation of therapy. Another side effect described in humans is lower thyroid hormone levels, which was also not observed in our case; the thyroid hormone level was higher $(25 \mathrm{nmol} / \mathrm{L})$ than at the beginning. This might suggest a connection between levels of IGF-I and thyroid hormones because therapy of congenital hypothyroidism leads to an increase in the level of IGF-1, which was previously low, in one described case (24). Further side effects, such as SCFE, were not observed on x-ray. Clinical signs of $\mathrm{BIH}$, such as headache, are hard to observe in cats, but vomiting was not observed.

Given all the facts, we can conclude that the cat suffered from dwarfism, which could be caused by severe infection and/or maldigestion. Pituitary dwarfism cannot be excluded either, since no advanced diagnostics were performed, and the IGF-1 was unmeasurably low at the beginning of the therapy.

\section{DATA AVAILABILITY STATEMENT}

The original contributions presented in the study are included in the article/supplementary material, further inquiries can be directed to the corresponding author.

\section{ETHICS STATEMENT}

Ethical review and approval was not required for the animal study because this was case report, cat owned of one of the authors. Written informed consent was obtained from the owners for the participation of their animal in this study.

\section{AUTHOR CONTRIBUTIONS}

$\mathrm{MN}$ created the concept of the work. $\mathrm{MN}, \mathrm{KNH}$, and $\mathrm{MF}$ collected the data and prepared the manuscript. MN and MF did the final check. All authors contributed to the article and approved the submitted version.

\section{ACKNOWLEDGMENTS}

We thank Sandra Milburn for the language editing. 


\section{REFERENCES}

1. Peréz-Alenza D. Pituitary GH deficiency and pituitary dwarfism. In: Feldman EC, Fracassi F, Peterson ME, editors. Feline Endocrinology. Milano: Edra Spa. (2019).

2. Reusch CE. Disorders of growth hormone. In: Feldman EC, Nelson RW, Reusch CE, Scott-Moncrieff JCR, Behrend EN, editors. Canine \& Feline Endocrinology, 4 Edn. St. Louis, Missouri: Elsevier (2015). p. 3776. doi: 10.1016/B978-1-4557-4456-5.00002-X

3. Langley-Hobbs S. Musculoskeletal oddities in the cat: an overview of some curious causes of lameness. J Feline Med Surg. (2012) 14:3142. doi: 10.1177/1098612X11432825

4. Polizopoulou ZS, Kazakos G, Patsikas MN, Roubies N. Hypervitaminosis A in the cat: a case report and review of the literature. J Feline Med Surg. (2005) 7:363-8. doi: 10.1016/j.jfms.2005.05.004

5. Dittmer KE, Thompson KG. Vitamin D metabolism and rickets in domestic animals: a review. Vet Pathol. (2011) 48:389407. doi: 10.1177/0300985810375240

6. Zafalon RVA, Ruberti B, Rentas MF, Amaral AR, Vendramini THA, Chacar FC, et al. The role of vitamin D in small animal bone metabolism. Metabolites. (2020) 10:496. doi: 10.3390/metabo10120496

7. Uhl EW. The pathology of vitamin D deficiency in domesticated animals: an evolutionary and comparative overview. Int J Paleopathol. (2018) 23:1009. doi: 10.1016/j.ijpp.2018.03.001

8. Zhu BY. Orthopedic manifestations of systemic disease. In: Ettinger SJ, Feldman EC, Cote E, editors. Textbook of Veterinary Internal Medicine eBook, 8 Edn. Amsterdam: Elsevier (2017). p. 433-9.

9. Peterson ME. Hypothyroidism. In: Feldman EC, Fracassi F, Peterson ME, editors. Feline Endocrinology. Milano: Edra S.p.a. (2019). p. 281-316.

10. Iturriaga MP, Cocio JA, Barrs VR. Cluster of cases of congenital feline goitrous hypothyroidism in a single hospital. J Small Anim Pract. (2020) 61:696-703.

11. Giudice E, Macrì F, Crinò $\mathrm{C}$, Viganò $\mathrm{F}$, Di Pietro $\mathrm{S}$. Hypoadrenocorticism in a young dwarf cat - case report. Vet Arh. (2016) 86:591-600.

12. Buckley RM, Davis BW, Brashear WA, Farias FHG, Kuroki K, Graves $\mathrm{T}$, et al. A new domestic cat genome assembly based on long sequence reads empowers feline genomic medicine and identifies a novel gene for dwarfism. PLoS Genet. (2020) 16:e1008926. doi: 10.1101/2020.01.06.8 96258

13. Donaldson D, Billson FM, Scase TJ, Sparkes AH, McConnell F, Mould JR, et al. Congenital hyposomatotropism in a domestic shorthair cat presenting with congenital corneal oedema. I Small Anim Pract. (2008) 49:3069. doi: 10.1111/j.1748-5827.2007.00517.x

14. König ML, Henke D, Adamik K, Pérez Vera C. Juvenile hyposomatotropism in a Somali cat presenting with seizures due to intermittent hypoglycaemia. JFMS Open Rep. (2018) 4:2055116918761441. doi: 10.1177/2055116918 761441

15. Voorbij AM, van Steenbeek FG, Vos-Loohuis M, Martens EE, HansonNilsson JM, van Oost BA, et al. A contracted DNA repeat in LHX3 intron 5 is associated with aberrant splicing and pituitary dwarfism in German shepherd dogs. PLoS One. (2011) 6:e27940. doi: 10.1371/journal.pone.00 27940

16. Voorbij AM, Leegwater PA, Kooistra HS. Pituitary dwarfism in Saarloos and Czechoslovakian wolfdogs is associated with a mutation in LHX3. J Vet Intern Med. (2014) 28:1770-4. doi: 10.1111/jvim. 12448

17. Greco DS. Pituitary deficiencies. Top Companion Anim Med. (2012) 27:27. doi: 10.1053/j.tcam.2012.04.002

18. Gold H, Spector S, Samaan NA, Pearson OH. Effect of growth hormone on carbohydrate metabolism in hypopituitary dwarfs. Metabolism. (1968) 17:74-83. doi: 10.1016/S0026-0495(68) 80009-5

19. Niessen SJM. Feline growth hormone disorders. In: Ettinger SJ, Feldman EC, Cote E, editors. Textbook of Veterinary Internal Medicine - eBook, $8 \mathrm{Edn}$. Amsterdam: Elsevier (2017).
20. Kooistra HS. Canine growth hormone disorders. In: Ettinger SJ, Feldman EC, Cote E, editors. Textbook of Veterinary Internal Medicine - eBook, $8 \mathrm{Edn}$. Amsterdam: Elsevier (2017). p. 4146-56.

21. Niessen SJ, Khalid M, Petrie G, Church DB. Validation and application of a radioimmunoassay for ovine growth hormone in the diagnosis of acromegaly in cats. Vet Rec. (2007) 160:902-7. doi: 10.1136/vr.160. 26.902

22. Kooistra HS, Voorhout G, Mol JA, Rijnberk A. Combined pituitary hormone deficiency in German shepherd dogs with dwarfism. Domest Anim Endocrinol. (2000) 19:177-90. doi: 10.1016/S0739-7240(00) 00074-6

23. Muñoz A, Riber C, Trigo P, Castejón F. Pathological changes and clinical use of the measurement of serum/plasma concentrations of insulin-like growth factor type. Hum Vet Med. (2010) 2:39-54.

24. Quante S, Fracassi F, Gorgas D, Kircher PR, Boretti FS, Ohlerth S, et al. Congenital hypothyroidism in a kitten resulting in decreased IGF-I concentration and abnormal liver function tests. J Feline Med Surg. (2010) 12:487-90. doi: 10.1016/j.jfms.2010.01.013

25. Richmond E, Rogol AD. Treatment of growth hormone deficiency in children, adolescents and at the transitional age. Best Pract Res Clin Endocrinol Metab. (2016) 30:749-55. doi: 10.1016/j.beem.2016. 11.005

26. van Herpen H, Rijnberk A, Mol JA. Production of antibodies to biosynthetic human growth hormone in the dog. Vet Rec. (1994) 134:171. doi: 10.1136/vr.134.7.171

27. Ascacio-Martínez JA, Barrera-Saldaña HA. A dog growth hormone cDNA codes for a mature protein identical to pig growth hormone. Gene. (1994) 143:277-80. doi: 10.1016/0378-1119(94)90110-4

28. Ogilvy-Stuart AL. Growth hormone deficiency (GHD) from birth to 2 years of age: diagnostic specifics of GHD during the early phase of life. Horm Res. (2003) 60:2-9. doi: 10.1159/000071219

29. Acharya SV, Gopal RA, Bandgar TR, Menon PS, Shah NS. Prepubertal gynecomastia a rare complication of growth hormone therapy. Indian $\mathrm{J}$ Pediatr. (2010) 77:443-4. doi: 10.1007/s12098-010-0012-6

30. Loder RT. Slipped capital femoral epiphysis. Am Fam Phys. (1998) 57:213542, 48-50.

31. Darendeliler F, Karagiannis G, Wilton P. Headache, idiopathic intracranial hypertension and slipped capital femoral epiphysis during growth hormone treatment: a safety update from the KIGS database. Horm Res. (2007) 68(Suppl. 5):41-7. doi: 10.1159/000110474

32. Souza FM, Collet-Solberg PF. Adverse effects of growth hormone replacement therapy in children. Brasileiros de Endocrinologia Metabologia. (2011) 55:55965. doi: 10.1590/S0004-27302011000800009

33. Martin P. An Experimental study of weaning in the domestic cat. Behaviour. (1986) 99:221-49. doi: 10.1163/156853986X00568

34. Pineda C, Aguilera-Tejero E, Guerrero F, Raya AI, Rodriguez M, Lopez I. Mineral metabolism in growing cats: changes in the values of blood parameters with age. J Feline Med Surg. (2013) 15:86671. doi: 10.1177/1098612X13478264

35. Coulson A, Noreen L. An Atlas of Interpretative Radiographic Anatomy of the Dog \& Cat Osney Mead. Oxford: Blackwell Science (2002). p. 376437. doi: 10.1002/9780470690260

36. Wit JM, Rekers-Mombarg LT, Cutler GB, Crowe B, Beck TJ, Roberts K, et al. Growth hormone $(\mathrm{GH})$ treatment to final height in children with idiopathic short stature: evidence for a dose effect. J Pediatr. (2005) 146:4553. doi: 10.1016/j.jpeds.2004.08.055

37. Kaptein EM, Hays MT, Ferguson DC. Thyroid hormone metabolism. A comparative evaluation. Vet Clin North Am Small Anim Pract. (1994) 24:43166. doi: 10.1016/S0195-5616(94)50051-2

38. Gregus Z, Watkins JB, Thompson TN, Harvey MJ, Rozman K, Klaassen CD. Hepatic phase I and phase II biotransformations in quail and trout: comparison to other species commonly used in toxicity testing. Toxicol Appl Pharmacol. (1983) 67:430-41. doi: 10.1016/0041-008X(83)90327-7

39. Nicolson A, Toogood AA, Rahim A, Shalet SM. The prevalence of severe growth hormone deficiency in adults who received growth hormone replacement in childhood [see comment]. Clin Endocrinol (Oxf). (1996) 44:311-6. doi: 10.1046/j.1365-2265.1996.671492.x 
40. Salerno M, Di Maio S, Ferri P, Lettiero T, Di Maria F, Vajro P. Liver abnormalities during growth hormone treatment. $J$ Pediatr Gastroenterol Nutr. (2000) 31:149-51. doi: 10.1097/00005176-20000800 0-00011

Conflict of Interest: The authors declare that the research was conducted in the absence of any commercial or financial relationships that could be construed as a potential conflict of interest.

Publisher's Note: All claims expressed in this article are solely those of the authors and do not necessarily represent those of their affiliated organizations, or those of the publisher, the editors and the reviewers. Any product that may be evaluated in this article, or claim that may be made by its manufacturer, is not guaranteed or endorsed by the publisher.

Copyright (๑ 2021 Načeradská, Návojová Horáčková and Fridrichová. This is an open-access article distributed under the terms of the Creative Commons Attribution License (CC BY). The use, distribution or reproduction in other forums is permitted, provided the original author(s) and the copyright owner(s) are credited and that the original publication in this journal is cited, in accordance with accepted academic practice. No use, distribution or reproduction is permitted which does not comply with these terms. 